\title{
Avaliação da Adequação e Eficácia de Programas de Marketing de Destinos Turísticos: uma análise de Balneário Camboriú - Santa Catarina, Brasil
}

\author{
Evaluation of the Adequacy and Efficacy of Marketing Programs: an analisis \\ of Balneário Camboriú - Santa Catarina, Brazil
}

Guilherme Guimarães Santana ${ }^{1}$

\begin{abstract}
Resumo
Um dos setores mais beneficiados com a estabilização da economia brasileira a partir dos meados dos anos 90 foi o do turismo. Neste contexto, o investimento por parte dos órgãos oficiais de turismo em marketing se tornou uma das ferramentas estratégicas mais importantes para o crescimento de um destino turístico. Esta pesquisa avaliou a adequação e eficácia dos programas de marketing de Balneário Camboriú - SC, um dos principais destinos turísticos brasileiro. Para isto, utilizou-se métodos multivariados de análise, neste caso análise fatorial. Os resultados indicam que os programas de marketing desenvolvidos e implementados pela Secretaria de Turismo de Balneário Camboriú têm um nível de adequação e eficácia não muito satisfatório. Ficou evidente que a maior demanda para Balneário Camboriú se dá por outros motivos, e não fruto dos esforços de marketing da Secretaria de Turismo municipal.
\end{abstract}

Palavras-chave: marketing turístico; adequação; eficácia; Balneário Camboriú.

\begin{abstract}
Tourism is one of the sectors that most benefited from the economic stabilization of the Brazilian economy since mid 90s. In this context, public marketing investment became one of the most important strategic tools to develop a tourism destination. This study evaluated the adequacy and efficacy of the marketing program of Balneário Camboriú, one of the most important Brazilian destinations. Multivariate analysis, in this case Factor Analysis, was employed to achieve such a goal. The results suggest that the marketing programs developed and implemented by the Tourism Authority of Balneário Camboriú have a low level of adequacy and efficacy. It became evidently clear that the majority of the tourism demand to Balneário Camboriú derived from reasons other than those related to the marketing efforts of the local Tourism Authority.
\end{abstract}

Keywords: tourism marketing; adequacy; efficacy; Balneário Camboriú.

\footnotetext{
${ }^{1} \mathrm{PhD}$ Visiting Scholar, Department of Economics and International Studies, Innsbruck University, Áustria. Email: ggs112003@yahoo.com
} 


\section{Introdução}

O mercado turístico doméstico aumentou significativamente após a reestruturação da economia brasileira que teve início em 1994 (CARVALHO, 2004; PIRES, 2004; EMBRATUR, 2004a; SANTANA, 2000; EMBRATUR, 1999a). Podendo poupar e planejar suas economias, os consumidores não só mudaram seus padrões de compras mas começaram a ter acesso a outras modalidades de consumo, como por exemplo às viagens nacionais e internacionais. O mercado internacional de viagens também se sentiu atraído pelas novas facilidades, atrações, e produtos desenvolvidos no Brasil a partir do plano real de 1994. Os governos, federal e estaduais, assim como os municipais, despertaram para os benefícios do turismo e várias iniciativas surgiram, como por exemplo o PNMT (Plano Nacional de Municipalização do Turismo) da EMBRATUR. Linhas de créditos, através de agências nacionais e internacionais, fundos de pensões, e outros, foram criadas e colocadas à disposição do empresariado do trade turístico em geral e de governos locais. O investimento no turismo no Brasil cresceu dramaticamente nos últimos anos. Várias cadeias internacionais de hotéis operam hoje no Brasil, foram formados consórcios nacionais e internacionais, e o setor vive uma expansão sem precedentes (CARVALHO, 2004; PIRES, 2004; EMBRATUR, 2004a; SANTANA, 2001). Por exemplo, o investimento privado no setor em 1998 ultrapassou US\$ 6 bilhões (SCHNEIDER, 1999). Segundo análise da EMBRATUR (2004a, 2004b), não só o investimento privado vem crescendo, mas também o investimento de instituições públicas têm aumentado drasticamente nos últimos anos (BNDES, Banco do Brasil, Caixa Econômica Federal, Bancos Regionais, etc.). A receita do turismo internacional no Brasil em 2004 foi de US\$ 3.2 bilhões, segundo dados do Boletim de Desempenho Econômico do Turismo (BRASIL - Ministério do Turismo, 2005), que projetava para 2005 uma receita de US\$ 4 bilhões, um aumento de quase 25\%. A contribuição do setor (turismo doméstico e internacional juntos) para a economia brasileira é significativa. Já em 1998, superou os US\$18 bilhões, ou 3.4\% do Produto Interno Bruto do país (EMBRATUR, 1999a). O turismo já representava, em termos de exportações, o segundo produto nacional, ficando atrás somente da soja e superando produtos de exportação tradicionais tais como ferro, minerais, café e açúcar (EMBRATUR, 1999b).

Inevitavelmente, cresceu ainda mais a concorrência entre os destinos turísticos (sejam estes regiões, atrações turísticas, ou produtos). Algumas regiões, como o Nordeste, por exemplo, se 
organizaram e formaram ações conjuntas de desenvolvimento e de marketing. Outras resolveram continuar "independentes" como uma opção estratégica. O fato é que o investimento por parte dos órgãos oficiais de turismo (EMBRATUR - em níveis nacional e internacional, secretarias estaduais, municipais, e outras entidades ligadas ao setor) em marketing, a ferramenta estratégica mais importante para o crescimento do turismo nos destinos, cresceu exponencialmente nos últimos anos e representa hoje somas significativas dos orçamentos destes órgãos.

Sendo grande parte, quando não totalmente, destes programas de marketing financiados pelos cofres públicos, fez-se necessário uma avaliação rigorosa dos efeitos destes programas e investimentos, utilizando modelos sofisticados de análise. Esta pesquisa teve o propósito de avaliar a adequação e eficácia dos programas de marketing do órgão oficial de turismo de Balneário Camboriú. Para isso abordou-se os temas afins, fazendo uma revisão bibliográfica abrangente dos tópicos e de pesquisas realizadas não só no Brasil, mas também no exterior, e foi feita uma pesquisa junto a 300 turistas e a entidades (100 ao todo) que compõem o mix do trade turístico de Balneário Camboriú na temporada de verão 2004/2005. Para a análise dos dados, foi utilizado método multivariados de pesquisa, em especial a análise fatorial.

Este artigo aborda inicialmente as questões referentes à temática central da avaliação da eficácia e adequação dos programas de marketing através de uma revisão abrangente da literatura. Em seguida, descreve e discute as metodologias empregadas para atingir os objetivos da pesquisa, e por fim, apresenta os resultados, discussão e conclusões.

\section{Marketing Turístico - Adequação e Eficácia}

Na literatura internacional de marketing turístico o fluxo turístico é atribuído à combinação de dois fatores: fator "push” (“generating”) e ao fator "pull“ (“attracting”) (RICHARDSON e FLUKER, 2004; MANSFELD, 1990; MURPHY, 1985; PEARCE, 1987). Os fatores “push” são formados a partir do turista, como, por exemplo, poder econômico, necessidades de viagens, motivações de viagens, comportamentos formais e informações em relação a viagens, e grau de exposição às informações turísticas (BLANK, 1989; SMITH, 1989). Os custos envolvidos em atividades de viagens são particularmente importantes no sentido de que eles determinam a propensão de viagens internacionais. Mesmo que estes fatores acima gerem fluxo turístico, eles têm uma relevância irrisória nos comportamentos das tendências do 
turismo. Teoricamente, qualquer destino poderia gerar demanda (fluxo) através destes fatores se baixasse o preço significativamente. No entanto, a escolha de um destino é determinada pela avaliação dos turistas dos atributos do destino e pela utilidade (numa escala de valores) atribuída pelos turistas (HUYBERS, 2003; PAPATHEODOROU, 2001), o que é conhecido como o fator “pull” (KIM e FESENMAIER, 1990; DILLEY, 1986). Nesta conceitualização, a imagem construída pelo turista tem um papel fundamental na avaliação dos atributos e utilidade do destino.

Imagem, para este propósito, pode ser definido como as crenças, idéias, sentimentos, expectativas e impressões de uma pessoa sobre um destino (DANN, 1996; DRISCOLL et al, 1994; BROWN, 1992; MOUTINHO, 1987; BETTMAN e PARK, 1980; CROMPTON, 1979). A imagem de um lugar provem de experiências pessoais ou de informações secundárias, como por exemplo conversas pessoais, mídia, e de exposição aos programas de marketing (promoção, etc.). Gunn (1989), argumenta que as imagens de destinos evoluem em dois níveis diferentes: “imagem orgânica” e "imagem induzida”. A imagem "orgânica” é comunicada através dos discursos educacionais, e pela mídia escrita e eletrônica. A imagem “induzida” por sua vez, é também uma imagem institucional mas é gerada através de eventos, símbolos e campanhas publicitárias feitas pelos órgãos oficiais de turismo.

Os órgãos oficiais de turismo foram formados para produzirem uma imagem positiva e diferenciada de seus destinos e para promoverem uma experiência única para os seus visitantes. O marketing estratégico dos órgãos oficiais de turismo se tornou uma ferramenta essencial para encorajar os turistas a viajarem para um determinado destino. Desta forma, os programas de marketing de destinos “vendem” um produto único que possui tanto uma experiência única como também uma vasta gama de atributos como belezas naturais, alto valor utilitário, clima, localização geográfica, qualidade das facilidades e serviços, hospitalidade, segurança, história, costumes locais e comércio, dentre outros atributos. Slogans, eventos, símbolos e campanhas publicitárias são produzidos pelos órgãos oficiais de turismo especialmente para diferenciar os seus destinos no mercado global. Uma das conseqüências do marketing institucionalizado e controlado pelo poder público é a “reprodução” da interpretação da realidade (feita pelos órgãos públicos) através de seus programas de marketing. Faz-se, então, necessário uma avaliação do nível de adequação e da eficácia dos programas de marketing. Estudos desta natureza têm se tornado uma constante em várias partes do mundo devido aos grandes benefícios que trazem aos órgãos públicos e ao turismo em geral. Pesquisadores como Hunt (1991), Woodside (1990), Mok (1990), Goss 
(1993), Peattie e Peattie (1996), Syrakaya et al (1995), Tellis e Gaeth (1990), Park et al(1988), Neslin, Henderson e Quelch (1985), dentre outros, demonstraram que através de pesquisas sobre a adequação e eficácia dos programas de marketing, os órgãos públicos não só se legitimam perante seus contribuintes e a opinião pública em geral, mas também há uma melhora significativa nos resultados dos programas. Entre outras vantagens de uma avaliação da eficácia dos programas de marketing, pode-se ainda citar:

- Esclarecimento de objetivos;

- Identificação de oportunidades;

- Aumento de flexibilidade e adaptabilidade das ações de marketing perante as constantes mudanças no mercado;

- Fluxo constante de informações do ambiente operacional;

- Melhor e mais eficiente alocação de recursos;

- Etc.

Conclui-se, então, que a avaliação de programas de marketing é de extrema importância pelos benefícios oferecidos. Em análise, é importante tanto como um instrumento pró-ativo (proporcionando informações cruciais para o processo de tomadas de decisões), quanto como instrumento de retrospectiva (avaliando os resultados de decisões passadas e dos programas de marketing decorridos dessas decisões). É importante ainda ressaltar que a literatura brasileira sobre este assunto ainda é bastante incipiente. A intensa busca de informações sobre estudos ou esforços semelhantes no Brasil antes e durante o desenvolvimento desta pesquisa não surtiu nenhum efeito prático. Portanto, acredita-se que a abordagem à temática tem um certo pioneirismo no Brasil e que os resultados obtidos possam contribuir para outras iniciativas de pesquisa.

\section{Metodologia}

Avaliação pode ser definida como um processo sistemático para medir objetivamente a performance de uma organização ou programa. Neste processo de avaliação de programas, geralmente, aplicam-se 3 (três) critérios fundamentais:

a - Adequação (até onde os objetivos e prioridades dos programas de marketing vão ao encontro das necessidades dos clientes e stakeholders); 
b - Eficácia (até onde os programas atingiram os seus objetivos);

c - Eficiência (até onde os resultados dos programas são atingidos a um custo aceitável e dentro de uma escala de tempo razoável).

A adequação, especificamente, requer algumas considerações porque nos auxilia a definir a orientação dos programas dos órgãos oficiais de turismo. A maioria dos órgãos oficiais de turismo vê como sendo as suas missões o incremento das suas receitas provenientes de turismo através de uma fatia maior de mercado. Esta missão, no entanto, está sujeita a algumas questões:

1 - A ênfase no incremento nos números de turistas inevitavelmente fazem com que os órgãos oficiais de turismo se preocupem exclusivamente com aspectos promocionais de marketing e se esqueçam do papel mais abrangente do marketing.

2 - De um modo geral, os órgãos oficiais de turismo expressam as suas ambições de fatia de mercado em termos de número de turistas, mesmo que as receitas provenientes do turismo possam ser aumentadas através de outros meios do que simplesmente aumentando o número de visitantes para um destino. De fato, existem argumentos em prol do uso de outros indicadores que não somente o número de visitantes/turistas. Por exemplo, alguns autores argumentam que o meio mais eficiente de medir a demanda turística é o número de noites em um destino (PARASKEVOPOULOS, 1977), enquanto outros sugerem que um parâmetro mais eficiente seria os gastos de turistas em um destino (O'HAGAN e HARRISON, 1984). Entretanto, medir e comparar dados entre diversos segmentos de mercados e destinos de acordo com estas duas últimas opções implica em sérias dificuldades, uma vez que tanto número de noites em um destino quanto gasto, geralmente apresentam dificuldades de ordem logística e também de credibilidade (dados, quando existem, não são fiáveis). A maioria das discussões se forma em torno do número de visitantes para um destino (BARRY e O'HAGAN, 1972). Sendo assim, esta pesquisa utilizou como parâmetro o número de visitantes para Balneário Camboriú para satisfazer parte de seus objetivos.

A avaliação da eficácia de programas de marketing requer algumas considerações sobre outros fatores que poderiam influenciar o mercado além da simples atribuição dos resultados às ações dos órgãos oficiais de turismo. Existem inúmeros outros fatores que têm o potencial de impactar e influenciar no número de turistas. É essencial, então, que outros métodos de análises sejam empregados para que se tenha uma visão global da eficácia dos programas de 
marketing. Para este efeito, pode-se utilizar “Tracking Analysis”. “Tracking”, em essência, é um método que monitora as mudanças na consciência (awareness), interesse, preferência, e intenções como uma conseqüência da exposição de turistas aos programas de divulgação. Entretanto, o uso de estudos de “Tracking” não é necessariamente suficiente para demonstrar a eficácia de um programa de marketing. Isto é, uma mudança na predisposição do mercado em potencial em relação a um destino em particular, não é automaticamente transformado em viagens para aquele destino. No entanto, “Tracking” ajuda a estabelecer o primeiro elo da cadeia causal.

Considerando a discussão acima, pode ser concluído que o mais importante então seria o uso de técnicas que medissem o efeito dos programas em pessoas que realmente viajam para um destino. Para isso, “Conversation Studies” é um método freqüentemente utilizado. Mok (1990), esclarece e demonstra a importância deste método em avaliar a eficácia de programas de marketing na indústria do turismo. No entanto, ambos os métodos (“Traking” e “Conversation”), mesmo que sejam instrumentais para o assunto abordado, ainda são insuficientes para proporcionar um resultado satisfatório. Ambos apresentam limitações consideráveis que comprometeriam os resultados, uma vez que vários fatores, e não só as campanhas publicitárias e de divulgação dos órgãos oficiais de turismo, contribuem para as decisões das pessoas em se engajarem em viagens.

Os métodos multivariados de análises têm o potencial de proporcionar as bases para uma avaliação da eficácia dos programas de marketing uma vez que têm a habilidade de identificar e quantificar o impacto de uma grande gama de fatores (FAULKNER, 2003). A inclinação ou tendência para viajar em um determinado mercado depende de uma combinação de fatores e condições sócio-econômicas que variam e que têm de ser vistas e analisadas considerando um contexto mais abrangente. Sendo assim, análise fatorial foi empregada para medir a eficácia dos programas de marketing de Balneário Camboriú.

Devido às limitações de recursos e tempo, esta pesquisa não abordou o terceiro critério (eficiência) na avaliação dos programas de marketing da Secretaria de Turismo, ficando assim para um estudo futuro.

Para esta pesquisa foram aplicados 300 questionários a turistas de Balneário Camboriú (brasileiros e argentinos) e 100 a diversos membros/entidades que compõem o trade turístico (hotéis, restaurantes, lojas, etc.) do destino. Esta pesquisa foi aplicada durante os meses de 
dezembro de 2004 a março de 2005 (dezembro - jovens; janeiro e fevereiro - famílias e jovens; março - terceira idade). Desta forma, foi possível obter uma maior representatividade dos vários segmentos da demanda turística de Balneário Camboriú e do impacto dos programas oficiais de marketing sobre cada um deles. O tipo de pesquisa utilizado foi a exploratória - quantitativa, e os instrumentos de pesquisa primária foram questionários estruturados. A formulação dos questionários seguiu as orientações de Hair et. al. (2000), Malhotra (1996) e Churchill Jr. (1995). A disponibilização no questionário das racionalizações foi aleatória, buscando assim minimizar o impacto do viés relativo a ordenação lógica. O pré-teste do instrumento foi aplicado a 50 sujeitos, sendo que não foi necessário nenhum ajuste. Esta pesquisa também fez uso de relatórios, estatísticas oficiais do órgão de turismo de Balneário Camboriú, assim como de dados de outras entidades voltadas para o turismo. Para análise dos dados primários foi utilizado o método multivariado Análise Fatorial, associada ao método de análise de componentes principais, através do Statistical Package for Social Sciences - SPSS, Versão 9. Por questões metodológicas, foi desenvolvido um sistema de Zoneamento Turístico para Balneário Camboriú. O intuito de dividir a cidade em zonas foi o de, mais uma vez, buscar maior representatividade, uma vez que o perfil dos turistas que freqüentam o destino muda de zona para zona. De acordo com cada zona uma amostragem foi selecionada aleatoriamente. Em cada zona foram feitas em média 50 entrevistas com os turistas. Esta abordagem se justifica porque, como ficará claro abaixo, o marketing da cidade é genérico, dirigido a todos os segmentos. Portanto, para elucidar a adequação e a eficácia dos programas é preciso observar seus efeitos nos mais diversificados segmentos do mercado turístico.

Quadro 1 - Entrevistas por Zona Turística de Balneário Camboriú

\begin{tabular}{|l|l|c|c|}
\hline & Argentina & Brasil & Total \\
\hline Zona 1 & 19 & 38 & 57 \\
\hline Zona 2 & 40 & 16 & 56 \\
\hline Zona 3 & 28 & 23 & 51 \\
\hline Zona 4 & 24 & 28 & 52 \\
\hline Zona 5 & 32 & 20 & 52 \\
\hline Zona 6 & 16 & 16 & 32 \\
\hline
\end{tabular}

Nota: Entrevistas realizadas por zona a turistas brasileiros e argentinos. 


\section{Resultados - Análise Inicial}

\subsection{Perfil da demanda turística - verão 2004/2005}

Balneário Camboriú recebe durante a temporada de verão um número muito elevado de turistas, entre estes muitos brasileiros, argentinos, paraguaios e uruguaios. A diversidade, em termos de faixa etária dos freqüentadores da cidade, é muito grande. No mês de dezembro o mercado turístico é caracterizado pelo segmento jovem (15 a 25 anos). Em janeiro, predominam os segmentos dos jovens e famílias, e nos meses de fevereiro e março o mercado de Balneário Camboriú é composto por famílias e idosos (terceira idade). De um modo geral, Balneário Camboriú é um destino tipicamente familiar. A Gráfico 1 abaixo ilustra a estrutura social de viagem dos freqüentadores de Balneário Camboriú.

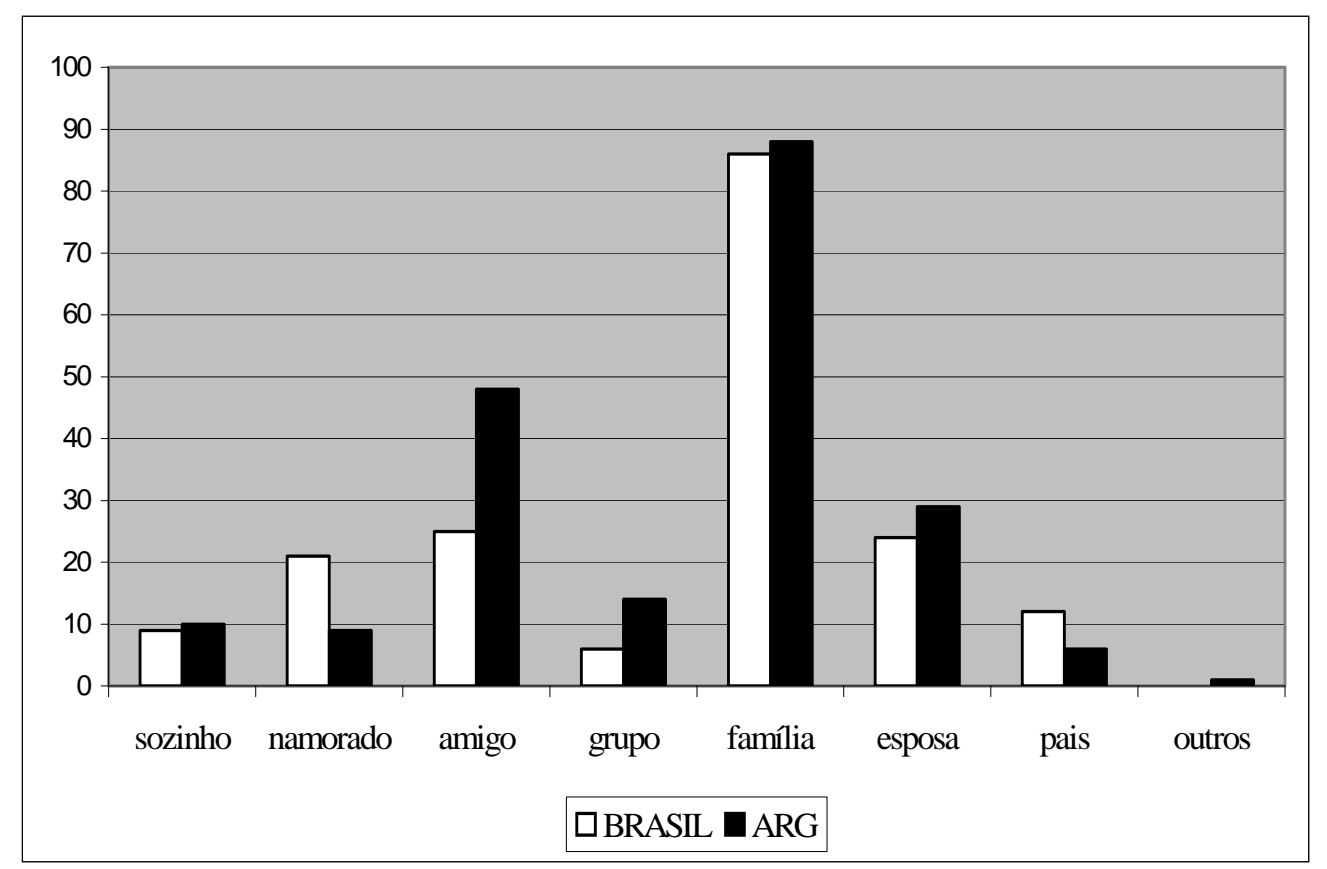

Gráfico 1 - Estrutura Social de Viagem - Brasileiros e Argentinos

O perfil da demanda turística de Balneário Camboriú no verão 2004/2005 foi bem heterogêneo, levando em consideração os seguintes aspectos: procedência, idade, grau de escolaridade, profissão e renda mensal líquida. Em relação ao nível de escolaridade dos entrevistados, os dados sugerem que os argentinos alcançaram uma média mais alta que os brasileiros e ainda demonstraram que a maioria dos turistas argentinos com a idade média de vinte anos ainda continua estudando, ou seja, ingressam no terceiro grau. Este dado contrasta 
com a realidade brasileira, onde a maioria dos turistas entrevistados desta faixa etária já desistiu do ensino superior. Em relação à procedência, os turistas brasileiros, na sua maioria, vieram do Mato Grosso, São Paulo, Paraná, Rio Grande do Sul e Santa Catarina. Já os turistas argentinos, vieram predominantemente das cidades de Córdoba, Buenos Aires, Missiones, Santa Fé, Tucumãn e Chaco.

Em dezembro, o predomínio foi de estudantes brasileiros e argentinos em Balneário Camboriú. Enquanto os estudantes brasileiros alegavam não ter renda mensal fixa, os argentinos contavam com receitas financeiras pequenas. Nos meses de janeiro e fevereiro as famílias tiveram seu lugar de destaque, juntamente com os jovens. A comparação entre a renda mensal líquida das famílias brasileiras e as argentinas revelou que as brasileiras têm em média de 10 a 15 salários mínimos, enquanto as argentinas, quase todas, contavam com renda acima de 18 salários mínimos.

\subsection{Programas de marketing desenvolvidos pela Secretaria de Turismo de Balneário Camboriú para o verão 2004/2005}

Os principais programas usados pela Secretaria de Turismo de Balneário Camboriú foram participações em feiras, eventos, congressos no Brasil e no exterior, a confecção e distribuição de vídeos, folhetos (sobre as atrações de Balneário Camboriú), programas para rádio, televisão, revistas de circulação regional e nacional, assim como para jornais. Para além disto, foram promovidos vários workshops em diversos estados brasileiros. A Secretaria de Turismo esteve também presente nas mais importantes feiras do Brasil com seu próprio stand ou como convidada ou parceira nos pavilhões da SANTUR (Santa Catarina Turismo).

Balneário Camboriú foi divulgado em vários veículos de comunicação fora do estado de Santa Catarina. De norte a sul do Brasil a imprensa em abrangência nacional, regional e local, apresentou ao público a infra-estrutura turística da cidade e seus principais atrativos. A divulgação foi conseqüência do trabalho da assessoria de imprensa da Secretaria de Turismo, através do envio mensal de releases, fotos e peças publicitárias da cidade, a mais de 800 veículos de comunicação do Brasil e exterior, bem como, na promoção de eventos (Famturs) trazendo jornalistas de outros estados para conhecer a cidade e seus produtos turísticos. Dentre os convidados destacam-se O Estado de São Paulo (SP), Jornal O Globo (RJ), Jornal do Brasil (RJ), Correio Brasiliense (DF), Revista Isto É (SP), Revista Chiques e Famosos 
(SP), Revista Veja (SP), e a Revista Photos. Este esforço da Secretaria de Turismo de Balneário Camboriú teve como objetivos:

1 - Aumentar o número de turistas em 37\% em relação ao verão de 2003/04,

2 - Aumentar o volume de transações no comércio, e

3 - Aumentar as oportunidades de emprego na cidade.

Segundo a diretoria de marketing da Secretaria de Turismo de Balneário Camboriú, o marketing da cidade é genérico, dirigido a todos os segmentos. Os recursos financeiros investidos em marketing para a temporada 2004/2005 não foram oficialmente disponibilizados, mas estima-se em R 4 milhões (quatro milhões de reais) os montantes envolvidos na promoção da cidade.

\subsection{Adequação e eficácia dos programas de marketing de Balneário Camboriú - análises de freqüência e crostabulação dos dados obtidos com os turistas}

Esta sessão explora os resultados obtidos da pesquisa com os turistas e combina duas análises, sendo que a análise de freqüência foi utilizada como uma análise inicial dos dados. Um dos objetivos deste estudo foi o de contrastar a percepção dos turistas (brasileiros e argentinos) em relação aos programas de marketing desenvolvidos pela Secretaria de Turismo de Balneário Camboriú. Para esta análise foi aplicado "Crostabulation Analysis", ou crostabulação.

O programa de marketing de Balneário Camboriú apresentado nas redes de televisão foi o que mais teve repercussão entre os turistas. No entanto, é importante observar que um grande número de turistas não esteve exposto a nenhum estímulo promocional, sugerindo que algo de errado possa ter ocorrido no processo de escolha de meios ou com as próprias estratégias de marketing da Secretaria de Turismo. A Gráfico 2 abaixo apresenta os diversos meios de comunicação utilizados pela Secretaria de Turismo para divulgar seus programas de marketing e indica quais foram os mais vistos pelos turistas antes da temporada 2004/2005. 


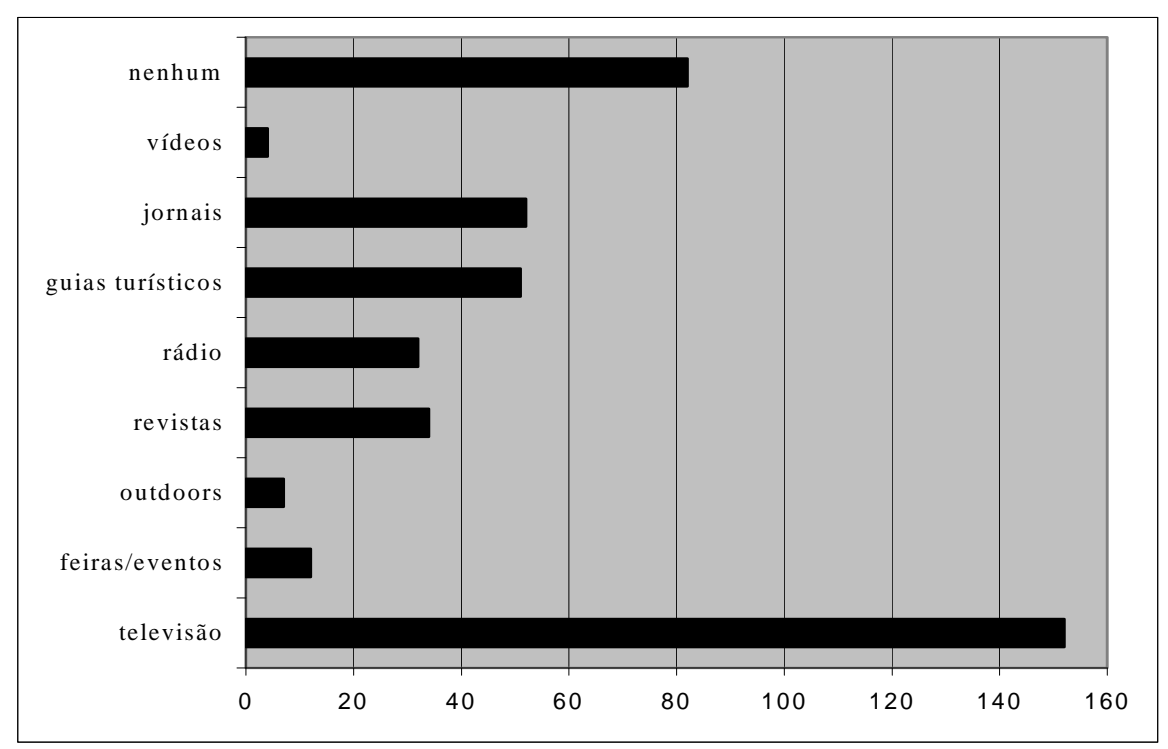

Gráfico 2 - Exposição dos Turistas aos Estímulos de Marketing por Veículos de Divulgação

Em relação ao comportamento de compras do mercado turístico de Balneário Camboriú, foi identificado que a maioria dos turistas, 74\%, decide para onde viajar com antecedência, consultando diversas fontes, incluindo amigos e familiares. Tanto brasileiros (73.8\%), como argentinos (74.2\%) não decidem viajar na última hora. De um modo geral, os turistas (57.7\%) consideram que amigos e familiares têm papel fundamental nas suas decisões de compra de um local para gozar férias. Para 60.4\% dos turistas argentinos, e 54.6\% dos turistas brasileiros, os relatos de amigos e familiares são fortes influenciadores na escolha do destino turístico.

A razão principal deste estudo foi a de avaliar a eficácia da campanha de marketing da Secretaria de Turismo de Balneário Camboriú. Neste sentido, não só os meios e veículos foram investigados, mas também a eficácia das mensagens utilizadas na campanha. Na opinião dos turistas, a mídia teve um papel secundário na escolha do destino. Apenas 24.8\% dos turistas brasileiros e $22.6 \%$ dos turistas argentinos acreditam que a mídia influenciou na decisão da viagem. Para além disto, e no que se refere à veracidade ou credibilidade dos comerciais veiculados pela Secretaria de Turismo sobre Balneário Camboriú, a metade dos turistas não teve confiança ou demonstrou incredulidade quanto às mensagens e conteúdos dos comerciais, e o restante ficou dividido entre não acreditar (25\%) e acreditar totalmente (25\%) nos comerciais. Foi surpreendente a constatação de que para mais da metade dos entrevistados brasileiros (58.1\%) o fator principal que os motivou a passar férias em 
Balneário Camboriú foi o fato de já possuírem, ou ter à disposição, residência na cidade. Se contrastado com a oferta de leitos na cidade, este dado tem fundamento. A população residente de Balneário Camboriú é de aproximadamente 80.000 habitantes. Esta realidade se transforma no verão quando a cidade acomoda 600.000 pessoas em um dado momento. Se for considerado que a rede hoteleira da cidade dispõe de aproximadamente 18.000 leitos, a grande maioria do restante (turistas) realmente se encontra em residências particulares, confirmando os dados obtidos. Já para os argentinos, o fator principal de escolha de Balneário Camboriú foi atribuído às belezas naturais da cidade e região. É interessante observar ainda que a Secretaria de Turismo de Balneário Camboriú investiu na divulgação de várias outras atrações, mas não deu ênfase especial às belezas naturais nos programas de marketing. A Tabela 1 abaixo demonstra os fatores que mais influenciaram os turistas de Balneário Camboriú na escolha do destino.

Tabela 1 - Principais Fatores que Influenciaram na Escolha de Balneário Camboriú

\begin{tabular}{|l|c|c|c|}
\hline & Brasil & $\begin{array}{c}\text { Argentin } \\
\mathbf{a}\end{array}$ & Total \\
\hline Relatos de outras pessoas & 21 & 61 & 82 \\
\hline Residência de amigos & 24 & 21 & 45 \\
\hline Residência familiar & $\mathbf{8 2}$ & 41 & 123 \\
\hline Vida noturna & 36 & 81 & 117 \\
\hline Teleférico/ Cristo & 12 & 20 & 32 \\
\hline Mais barato & 2 & 63 & 65 \\
\hline Mídia & 10 & 2 & 12 \\
\hline Comércio & 23 & 20 & 43 \\
\hline Eventos & 24 & 23 & 47 \\
\hline Belezas naturais & 38 & $\mathbf{8 9}$ & 127 \\
\hline Outros & 5 & 12 & 17 \\
\hline
\end{tabular}

A grande diversidade de produtos turísticos da cidade proporciona atrativos diferentes para cada faixa etária. Quer dizer, a opção por Balneário Camboriú também varia muito com a idade dos turistas. A Tabela 2 abaixo segmenta os dados discutidos acima sobre a motivação de escolha da cidade como destino de férias por faixas etárias. A maioria dos turistas brasileiros opta por vir para Balneário Camboriú por ter residência familiar, como constatado acima. 
Tabela 2 - Fatores Decisivos para a Escolha de Balneário Camboriú - Brasileiros

\begin{tabular}{||c|c|c|c|c|c|}
\hline & $\mathbf{1 5}$ à $\mathbf{2 4}$ anos & $\mathbf{2 5}$ à $\mathbf{3 4}$ anos & $\mathbf{3 5}$ à $\mathbf{6 5}$ anos & Acima de 65 & TOTAL \\
\hline RES. FAM & 38 & 12 & 28 & 1 & 79 \\
\hline RES. AMIG & 13 & 7 & 4 & - & 24 \\
\hline RELATOS & 9 & 11 & 1 & - & 21 \\
\hline NATUREZA & 14 & 18 & 6 & - & 38 \\
\hline V. NOTURNA & 25 & 5 & 6 & - & 36 \\
\hline COMÉRCIO & 16 & 1 & 1 & - & 18 \\
\hline EVENTOS & 8 & 1 & 2 & - & 11 \\
\hline MÍDIA & 3 & 5 & 1 & - & 9 \\
\hline BARATO & 1 & - & 1 & - & 2 \\
\hline TELEFÉRICO / & 5 & 2 & 5 & 1 & 13 \\
CRISTO LUZ & & & & & \\
\hline
\end{tabular}

As belezas naturais e a vida noturna compõem as principais motivações dos turistas argentinos (Tabela 3).

Tabela 3 - Fatores Decisivos para e Escolha de Balneário Camboriú - Argentinos

\begin{tabular}{|c|c|c|c|c|c|}
\hline & $\mathbf{1 5}$ à $\mathbf{2 4}$ anos & $\mathbf{2 5}$ à $\mathbf{3 4}$ anos & $\mathbf{3 5}$ à $\mathbf{6 5}$ anos & Acima de 65 & TOTAL \\
\hline RES. FAM & 25 & 9 & 10 & - & 44 \\
\hline RES. AMIG & 6 & 15 & 3 & - & 24 \\
\hline RELATOS & 25 & 12 & 25 & - & 62 \\
\hline NATUREZA & 34 & 17 & 26 & - & 77 \\
\hline V. NOTURNA & 37 & 23 & 21 & - & 81 \\
\hline COMÉRCIO & 4 & 12 & 5 & - & 21 \\
\hline EVENTOS & 15 & 8 & 3 & - & 26 \\
\hline MÍDIA & - & 1 & 1 & - & 2 \\
\hline BARATO & 19 & 18 & 23 & - & 60 \\
\hline $\begin{array}{c}\text { TELEFÉRICO / } \\
\text { CRISTO LUZ }\end{array}$ & 9 & 5 & 7 & - & 21 \\
\hline
\end{tabular}

Levando em consideração que 80\% dos turistas que visitou Balneário Camboriú na temporada 2004/2005 não consultou um agente de viagem, ou seja, a maioria dos turistas veio para Balneário Camboriú porque já tem residência familiar, residência de amigos, ou por já conhecerem Balneário Camboriú, deixa uma dúvida sobre os meios utilizados pela Secretaria de Turismo para divulgar a cidade. Apenas uma parte dos turistas argentinos, 22.6\%, consultou um agente de viagem. Já para os brasileiros, esta porcentagem é irrisória, 3.5 \%. Este dado confirma os dados obtidos pela EMBRATUR (2004c), os quais revelam que somente 23.2\% de todas as viagens ocorridas no Brasil em 2003 foram do tipo organizada, quer dizer, tiveram alguma forma de intermédio ou gerenciamento por parte de agentes de 
viagens, operadores turísticos etc. A constatação de que a maioria dos entrevistados já freqüenta Balneário Camboriú há vários anos também contribui para justificar estes resultados. Dos turistas argentinos, $41.5 \%$ estava tendo a sua primeira experiência, $12.5 \%$ estava visitando a cidade pela segunda vez, 3.1\% pela terceira vez e $42.9 \%$ visitou o destino mais de quatro vezes. Já os turistas brasileiros, 9.9\% visitava a cidade pela primeira vez, 10.6\% pela segunda vez, 7.0\% pela terceira vez e $72.3 \%$ já havia gozado férias na cidade por mais que quatro vezes.

As boas opções de comércio que Balneário Camboriú oferece para os turistas não influenciaram na decisão da viagem para $82.3 \%$ dos entrevistados. Por exemplo, os turistas argentinos (64.8\%) não optam por viajar para um destino baseado na diversificação da oferta do comércio. Por outro lado, as belezas naturais são atrativos fundamentais na decisão de viagem para 75\% dos turistas entrevistados. Da mesma forma, para 62.4\% dos brasileiros e 44.7\% dos argentinos, as opções de diversão do destino (casas noturnas, shows, atrações, etc.), foram fatores fundamentais para as suas decisões na escolha da cidade. Enquanto as atrações turísticas, que incluem as casas noturnas, shows, e outras atrações, foram peças fundamentais dos programas de marketing na divulgação da cidade, as belezas naturais não foram bem exploradas. Além da praia, somente algumas fotos do teleférico do Parque Unipraias, que passa por cima de uma vasta vegetação costeira, e do Parque da Santur, apareciam nos materiais promocionais como vídeos e folders.

A qualidade da infra-estrutura turística (hotéis, restaurantes, atrações, casas noturnas, etc.), foi um fator crucial na escolha de Balneário Camboriú para 80.7\% dos turistas entrevistados. Este fator influenciou positivamente a decisão de $76.7 \%$ dos argentinos entrevistados e $85.1 \%$ dos brasileiros. Este fator foi bastante explorado nos programas de marketing do município. Por outro lado, a segurança, fator considerado fundamental para $63.8 \%$ dos turistas brasileiros e $57.2 \%$ dos turistas argentinos na escolha de um destino, foi completamente ignorada nas ações de marketing.

Este estudo também se preocupou em identificar a imagem que Balneário Camboriú tem como destino turístico para os dois grupos entrevistados. Apesar da maioria dos turistas, tanto brasileiros como argentinos, ter uma boa impressão de Balneário Camboriú como cidade e destino turístico (eles classificam a cidade como turisticamente completa em serviços gerais, comércio, vida noturna, etc.), demonstrou ter conhecimento sobre os problemas de poluição 
da praia que apresentava altos índices de coliformes fecais, e principalmente sobre a infraestrutura (ruas, esgotos, calçadas, trânsito) que necessitava ser melhorada.

Uma das estratégias utilizadas pelo Município para aumentar o número de turistas na cidade foi a de enfatizar que Balneário Camboriú é um destino barato. Na Argentina, por exemplo, foram utilizados slogans como "Mucha playa e poca plata”. Os resultados desta pesquisa, referente à determinação da sensibilidade dos turistas a preço, indicaram que 2/3 dos entrevistados se importa com os custos de uma viagem e que não considerava Balneário Camboriú como um destino particularmente barato. Houve uma diferença de opinião significativa entre os brasileiros e argentinos, sendo que os últimos se beneficiavam, quando da realização desta pesquisa, do câmbio dólar/real favorável. Mesmo assim, para 56\% dos argentinos, os preços estavam muito acima de suas expectativas.

\subsection{Resultados da adequação e eficácia dos programas de marketing - trade turístico}

O trade turístico de Baneário Camboriú (hotéis, restaurantes, bares, lojas, etc.), assim como as associações de classes (Associação de Hotéis, CDL - Clube de Diretores Lojistas de Balneário Camboriú, Associação de Bares Restaurantes e Similares, etc.), principais interessados e beneficiários diretos dos programas de marketing do órgão oficial de turismo municipal, têm certo envolvimento com a Secretaria de Turismo de Balneário Camboriú na promoção da cidade. Não poderia ser muito diferente, afinal, são nestes lugares, ou nos estabelecimentos que as associações representam, que os turistas usarão os serviços quando no destino. Porém, isto não significa que todos estabelecimentos associados às entidades fazem parte do programa de marketing de Balneário Camboriú. A participação está condicionada a contribuições financeiras para os programas de marketing. Dos quarenta hotéis que participaram deste estudo, 37.5\% conhece muito bem os programas de marketing desenvolvidos pela Secretaria de Turismo, 25\% conhece pouco e 37.5\% não conhece nada sobre os programas. Desses hotéis, 62.5\% contribui financeiramente para com os programas de marketing da Secretaria de Turismo, e 37.5\% não trabalha de nenhuma forma com a Secretaria de Turismo, porque não sabiam da existência destes programas e/ou não foram convidados para participar. Ficou evidente que os hotéis que trabalham com a Secretaria de Turismo beneficiam-se do programa uma vez que estes estabelecimentos são divulgados pelos programas de marketing da Secretaria. 
Levando em consideração a eficácia destes programas, foi identificado que os mesmos são avaliados como eficazes para $70 \%$ dos hotéis, enquanto o restante $30 \%$ os julga como pouco eficazes. Estes últimos, deve ser ressaltado, não participam dos programas de marketing da Secretaria de Turismo. É interessante observar que nenhum hotel tem idéia da porcentagem de seus negócios que são gerados a partir das ações promovidas pela Secretaria de Turismo. Portanto, nem mesmo os estabelecimentos que contribuem financeiramente para com os programas de marketing do município têm o interesse de mensurar os seus resultados, ou retorno, provenientes de seus investimentos em marketing.

Foi dada a oportunidade aos entrevistados (dirigentes de hotéis) para que se posicionassem em relação ao futuro destas ações de marketing. Cerca de $20 \%$ está contente com estes programas, porém, $80 \%$ acha que uma melhora seria desejável e mesmo necessária. Por exemplo, a maioria considera importante o estabelecimento de reuniões periódicas para que sejam discutidos e desenvolvidos novos objetivos, e se mostraram interessados em participar ativamente na discussão e elaboração dos programas e ações de marketing da Secretaria de Turismo. Ficou evidente que a participação das entidades de classes que representam o setor se reduz à contribuição de recursos financeiros e não no efetivo planejamento de marketing e seus conteúdos.

Esta pesquisa também foi feita com quarenta restaurantes pré-selecionados: 32.5\% conhece muito bem os programas de marketing, $7.5 \%$ conhece muito, $22.5 \%$ pouco e $37.5 \%$ não conhece nada. Desses restaurantes, $40 \%$ contribui financeiramente para com a Secretaria de Turismo. O restante dos dirigentes de restaurantes (60\%) revelou que não participam por não terem sido convidados pela Secretaria de Turismo. Em relação à eficácia do programa, 37.5\% acha que são muito eficazes, $20 \%$ considera pouco eficazes, e $42.5 \%$ julga que não são nada eficazes. Considerando os benefícios destes programas para estes estabelecimentos, $45 \%$ dos dirigentes de restaurantes acha que são bastante beneficiados, $32.5 \%$ acha que são pouco beneficiados e $22.5 \%$ considera que não são beneficiados. No entanto, assim como no caso dos hotéis, estes estabelecimentos também não procuram medir objetivamente o retorno do investimento em marketing através da Secretaria de Turismo.

A opinião de $25 \%$ dos dirigentes destes estabelecimentos para os próximos verões é a de que deve haver uma melhora nos esforços de marketing, enquanto $15 \%$ considera que deve haver mais investimento no mercado doméstico. Para 37.5\% dos dirigentes entrevistados, os esforços devem ser concentrados na recuperação da imagem negativa da praia (principal 
produto turístico) que estava, na ocasião desta pesquisa, muita poluída. O programa de marketing da Secretaria de Turismo foi considerado bom por 30\% dos entrevistados, que julgaram não ser necessárias mudanças nos programas.

No caso do comércio, a contribuição para com os programas de marketing oficial parte do CDL (Clube de Diretores Lojistas de Balneário Camboriú), e não de lojas, individualmente. As lojas do Shopping Center Atlântico, o maior da cidade, contribuem financeiramente e os recursos são repassados à Secretaria de Turismo pela administração do Shopping.

Finalmente, é importante ressaltar que nenhum dos estabelecimentos participantes deste estudo revelou os valores destinados à Secretaria de Turismo.

\subsection{Análise fatorial}

Considerando os objetivos propostos, o tratamento estatístico dos dados foi feito utilizando-se da técnica de Análise Fatorial, associada ao método de análise de componentes principais. Apesar de ser esperado um resultado multidimensional, foi empregada a análise fatorial exploratória, uma vez que as dimensões a serem encontradas não foram estabelecidas a priori.

Inicialmente, foi feita uma análise da consistência interna das variáveis desenvolvidas para estabelecer as relações de percepção dos turistas sobre os programas de marketing da Secretaria de Turismo de Balneário Camboriú. Para isso, foi utilizado o “Cronbach’s Coefficient Alpha” - “Reliability Test” (MALHOTRA, 1996; CHURCHILL JR., 1979; HAIR et al., 1987). "Reliability Tests” estimam a proporção da variância observada nas respostas atribuídas a erros. A medida obtida para esta pesquisa é extremamente satisfatória uma vez que excede o mínimo aceitável de alpha coefficient sugerido por Nunally (1978) de 0.50, e por Churchill Jr. (1979) de 0.70. Alpha coefficients para as variáveis utilizadas foi de 0.8327, indicando uma forte consistência dos itens, e aprovando desta forma o instrumento utilizado. Em outras palavras, o composto do instrumento de pesquisa desenvolvido para este estudo é consistente e fiável em como ele mede as variáveis propostas nesta pesquisa.

As análises efetuadas dos dados obtidos com os turistas refletem o lado objetivo da posição/opinião dos mesmos em relação à temática estudada. Enquanto uma análise de freqüência indica os padrões e tendências nos resultados obtidos, a crostabulação fornece respostas para "quem" (agrupa e contrasta). No entanto, estas análises não são capazes de analisar os motivos ou razões que motivaram/condicionaram tais respostas. Esta pesquisa 
buscou entender a lógica que permeia estas opiniões e para isso as dimensões, ou underlying dimensions, foram estabelecidas. Com o objetivo de identificar as dimensões em que podem ser organizadas as variáveis, empregou-se a técnica de Análise de Componentes Principais como método de extração, a fim de examinar o conjunto de relações interdependentes (MALHOTRA, 1996), explicando as covariâncias e correlações entre as variáveis (JOHNSON e WICHERN, 1992), agrupando-as em fatores. Para a obtenção de fatores que traduzem grupos de variáveis relacionados aos objetivos desta pesquisa, foi adotado o padrão sugerido por Hair et. al. (1987), com autovalor (eigenvalue) igual ou superior a 1, sem definição prévia do número de fatores. As rotações foram feitas através de métodos ortogonais. Vários tipos de rotações foram experimentados. Dentre outros tipos de rotações (Equimax Rotation e Quartimax Rotation) que têm sido utilizadas com grande sucesso como uma abordagem analítica na busca de obter uma rotação ortogonal dos fatores (HAIR et al, 1987), a rotação Varimax foi a mais satisfatória de todas para este pesquisa. A rotação Varimax minimiza o número de variáveis com cargas altas sobre o fator (MALHOTRA, 1979; HAIR et al, 1987) por meio da maximização do quadro das variâncias das cargas dos fatores. Os resultados obtidos sugerem que a técnica de análise escolhida é adequada.

A literatura referente à análise fatorial indica que qualquer factor loading, ou carga, sobre um fator, acima de 0.30 é significante ou "saliente" (HAIR et. al., 1987). Este critério é tido como rigoroso. Para esta pesquisa, foi utilizada a carga sobre fator de 0.50. Quer dizer, quanto maior o tamanho absoluto da carga sobre o fator, maior será a importância da carga na interpretação do fator. Esta pesquisa também empregou outras cargas, como 0.30 e 0.40 . No entanto, o número de fatores extraídos foi o mesmo e somente poucas outras variáveis foram incluídas, não influenciando significativamente na interpretação dos fatores. Neste sentido, e considerando as incertezas quanto à avaliação de erro em análise fatorial, a utilização de um valor mais rigoroso assegura um maior nível de significado relativo ao fator.

Apesar de terem sido extraídos 5 (cinco) fatores, somente o primeiro fator foi utilizado. Uma das razões para isto é que foi verificado que a carga associada dos outros fatores apresentavam comunalidades baixas, não se enquadrando nos critérios estabelecidos de 0.50, como mencionado acima. O autovalor (eigenvalue) para o Fator 1 foi de $17.235 \%$ de variância. A solução fatorial, conforme descrito anteriormente, foi obtida através da análise de componente principal com rotação Varimax das variáveis originais. O fator 1 sugere “Conforto e Prazer”. Neste fator, fica evidente a preocupação dos turistas com a infraestrutura turística e de lazer assim como as belezas naturais. As belezas naturais são os 
maiores atrativos para os 300 turistas entrevistados e o relato dos amigos e parentes é o meio mais eficaz e utilizado como referência pelos entrevistados.

\section{Conclusão}

O marketing se tornou a ferramenta mais importante para os órgãos públicos do turismo para alcançarem os seus objetivos de aumento de fatia de mercado em meio à crescente concorrência entre destinos e produtos turísticos. Considerando que a escolha de um destino turístico é efetuada através da consideração de uma gama de fatores, e que grandes somas de recursos (públicos e privados) são empregados em políticas e programas de marketing de destino, faz-se necessário uma análise da adequação e eficácia destas políticas e campanhas. Através da aplicação de métodos multivariados de análise, esta pesquisa analisou a adequação e eficácia dos programas de marketing da Secretaria de Turismo de Balneário Camboriú para o verão 2004/2005.

Os dados obtidos com as entrevistas feitas com 300 turistas (argentinos e brasileiros) no verão 2004/2005 e com o trade turístico de Balneário Camboriú (100 entrevistas), revelam que os programas de marketing, na sua grande maioria, desenvolvidos pela Secretaria de Turismo de Balneário Camboriú se mostraram tanto inadequados quanto ineficazes.

A Secretaria de Turismo tem como estratégia o marketing não diferenciado, que consiste em ignorar as diferenças que possam existir entre os consumidores, interessando-se somente pelo "consumidor médio". Quer dizer, a Secretaria de Turismo ignora os diferentes segmentos que existem no mercado e pratica um marketing não diferenciado para todo o mercado. A literatura sobre segmentação de mercado considera esta abordagem não muito oportuna, pois não se pode atender todo o mercado (AAKER, 1995; KOTLER, 1990; DIERDONCK,1992). Uma análise de conteúdo dos programas não deixa dúvidas sobre esta opção estratégica. Como mencionado anteriormente, os programas de marketing consistem em promoção de workshops em diversos estados brasileiros, participações em feiras, eventos, congressos no Brasil e no exterior, desenvolvimento de programas para rádio e televisão, e a confecção de material promocional. Houve também um grande esforço institucional junto à mídia nacional e a de países sul americanos para a divulgação da cidade. 
A mídia escrita, recurso bastante utilizado pela Secretaria de Turismo, influencia muito pouco os turistas na decisão de viagem. Menos de 1/4 dos turistas brasileiros e argentinos acredita que a mídia influencia na decisão da viagem.

Apesar de grande investimento e esforço em promover a cidade através de feiras, eventos, workshops, etc. junto aos agentes de viagem no Brasil e no exterior, uma baixíssima porcentagem dos entrevistados (22.6\% dos turistas argentinos e 3.5\% dos brasileiros) consultou um agente de viagem. Tradicionalmente, a maioria das viagens no Brasil se encaixa na categoria "não organizada”. Dados da EMBRATUR (2004c) revelam que em 2003 somente 23.2\% de todas viagens feitas em território nacional utilizaram serviços de agentes de viagens e/ou operadores turísticos. Considerando esta característica, não se justifica tamanho investimento nesta abordagem.

Entre os meios utilizados para a divulgação dos programas de marketing, a televisão foi o que mais gerou resultados, sendo visto por metade dos turistas. É importante frisar que 26.6\% dos turistas não viu nenhum tipo de divulgação sobre Balneário Camboriú. No tocante ao conteúdo dos programas, foi apresentado para o público a infra-estrutura turística do destino e seus principais acontecimentos (atrações turísticas). No entanto, as belezas naturais (forte influenciador para 75\% dos turistas argentinos, e também para os turistas brasileiros) foram muito pouco exploradas. A segurança, fator crítico na escolha de um destino para a grande maioria dos turistas, não foi mencionada ou abordada em nenhuma ação de marketing.

Talvez, um dos dados mais interessantes desta pesquisa se refere à motivação dos turistas para visitar Balneário Camboriú. Os turistas brasileiros optam por visitar Balneário Camboriú por já terem residências familiares ou facilidade de acomodação na cidade. É também reveladora a constatação de que a grande maioria dos turistas entrevistados já terem gozado férias na cidade por mais de quatro vezes. Estes dois dados, portanto, se reforçam.

Outro objetivo da Secretaria de Turismo de Balneário Camboriú consiste em enfatizar as boas opções do comércio para atrair turistas. No entanto, apenas $17.7 \%$ dos turistas considera as opções de comércio que o destino turístico oferece na sua decisão de viagem.

Um dos parâmetros utilizados para medir a adequação dos programas de marketing foi o de observar as mudanças no número de turistas que visitam a cidade. A Secretaria de Turismo, como mencionado previamente, pretendia, através de seus esforços de marketing, aumentar em 37\% o número de visitantes na cidade em relação à temporada 2003/04. No entanto, os 
dados da própria secretaria sugerem que este objetivo ficou longe de ser alcançado, com um acréscimo de somente $0.8 \%$.

A análise do trade turístico (hotéis, restaurantes e lojas), os principais interessados e beneficiários diretos dos programas de marketing, revelou que poucos estabelecimentos trabalham com a Secretaria de Turismo de Balneário Camboriú. Somente 62.5\% dos hotéis trabalha junto com a Secretaria de Turismo. Vale ressaltar que o restante de 37.5\% dos hotéis manifestou desejo de trabalhar com a Secretaria de Turismo. Estes dados são consistentes na análise dos restaurantes. Somente $40 \%$ dos restaurantes trabalham com a Secretaria de Turismo. As lojas têm uma participação diferenciada dos hotéis e restaurante nas campanhas de marketing do município. Elas contribuem financeiramente para com o CDL, e no caso do Shopping Center Atlântico para com a administração do shopping, e estes repassam os recursos para a Secretaria de Turismo na divulgação.

O emprego de métodos multivariados de análise, através da análise de componentes principais (análise fatorial), provou ser uma opção muito satisfatória para este tipo de pesquisa, uma vez que permitiu observar as dimensões em que podem ser organizadas as variáveis. Os testes de consistência interna tiveram resultados positivos, suportando a escolha do instrumento. Os resultados da análise fatorial sugerem que a preocupação dos turistas com a infra-estrutura turística e de lazer, assim como as belezas naturais, são aspectos dominantes na consideração de escolha por Balneário Camboriú. As belezas naturais são os maiores atrativos para os 300 turistas entrevistados e o relato dos amigos e parentes é o meio mais eficaz e utilizado como referência pelos entrevistados.

Considerando os dados analisados, pode-se concluir que a demanda turística para Balneário Camboriú é, na sua maioria, por "inércia", e não fruto direto dos esforços de marketing da Secretaria de Turismo de Balneário Camboriú. Ou seja, muitos dos esforços de marketing não são adequados ou eficazes. Para o trade turístico, somente 20\% dos hotéis está contente com os programas de marketing. Os restaurantes parecem ser os únicos que consideram os programas eficazes (70\%). Este estudo demonstrou claramente que os recursos investidos nos programas de marketing da cidade não estão surtindo o efeito esperado, e que, na verdade, grandes quantias estão sendo empregadas em veículos ou meios inapropriados, caracterizando assim uma inadequação e ineficácia do emprego de recursos (público e privado) em prol da atividade turística. 


\section{Limitações do Estudo}

É importante salientar que esta foi uma pesquisa do tipo exploratória, e portanto, apresenta todas as limitações inerentes a esta abordagem de pesquisa. Devido a recursos e tempo escassos, esta pesquisa não abordou a variável eficiência.

\section{Sugestões para Futuros Estudos}

Esta pesquisa demonstrou que a metodologia aplicada foi satisfatória. Neste sentido, poderia ser replicada em outras realidades na sua totalidade, envolvendo tanto turistas quando o trade, ou somente com um ou outro. Como mencionado anteriormente, em uma avaliação de programas de marketing podem ser utilizados três critérios: adequação, eficácia, e eficiência. Devido à limitação de recursos e tempo, não foi possível verificar o terceiro item, eficiência, que mede até onde os resultados dos programas foram atingidos a um custo aceitável e dentro de uma escala de tempo razoável. Portanto, seria interessante verificar este item.

\section{Referências Bibliográficas}

AAKER, D. 1972. Developing Business Strategy, New York, John Wiley \& Sons Inc., 1995

BARRY, K; O’HAGAN, J. An Economic Study of Tourist Expenditure in Ireland, Economic and Social Review, V. 3, p. 143 - 161

BETTMAN, J., PARK, C. 1980. Effects of Prior Knowledge and Experience and Phase of the Choice Process on Consumer Decision - A Protocol Analysis, Journal of Consumer Research, V. 7, p. 234 248

BLANK, U. 1989. The Community Tourism Industry Imperative: The Necessity, The Opportunities, its Potential, State College, PA, Venture Publishing

BRASIL - Ministério do Turismo. Boletim de Desenvolvimento Econômico do Turismo. Out 2005. Disponível em: <http://www.turismo.gov.br/site/arquivos/dados_fatos/Boletimdedesempenho/ SumarioAnoIINo08out2005.pdf>. Acesso em: 13 Fev. 2006

BROWN, G. 1992. Tourism and Symbolic Consumption, in Johnson, P. Thomas, B. (Eds.), 1992, Choice and Demand in Tourism, Lisboa, Júlio Figueiro Ltda

CARVALHO, C. L. 2004. Turismo no Brasil: Novos Rumos. <http://www.embratur.gov.br>. Acesso em: 9 Set. 
CHURCHILL Jr., G. A. 1979. A Paradigm for Developing Better Measures of Marketing Construct, Journal of Marketing Research, V. 16 (1), p. 64 - 73

CROMPTON, J. 1979. Motivations for Pleasure Vacation, Annals of Tourism Research, V. 6, p. 408 424

DANN, G. 1996. Tourist's Images of Destination - An Alternative Analysis, Recent Advances in Tourism Marketing Research, p. 41 - 55

DIERDONCK, R. 1992. Success Strategies in a Service Economy, European Management Journal, V. 10 (3), p. 365 - 373

DILLEY, R. 1986. Tourism Brochures and Tourism Images, Canadian Geographer, V. 30, pp. 59 - 65

DRISCOLL, A., LAWSON, R., NIVEN, B. 1994. Measuring Tourist's Destinations Perceptions, Annals of Tourism Research, V. 21 (3), p. $499-511$

EMBRATUR - Instituto Brasileiro do Turismo, Anuário Estatístico 2004. 2004a. Disponível em: $<$ http://www.turismo.gov.br/site/arquivos/dados_fatos/Anuario/anuarioEstatistico\%202004_ultima\%2 0Versao\%2031_12_2004.pdf>. Acesso em: 13 Fev. 2006

EMBRATUR - Instituto Brasileiro do Turismo. Estatísticas Básicas do Turismo - 2004. 2004b. Disponível em: <http://www.turismo.gov.br/site/arquivos/dados_fatos/evolucao/Estatisticas BasicasdoTurismo.pdf>. Acesso em: 13 Fev. 2006

EMBRATUR - Instituto Brasileiro do Turismo. Estudo da Demanda Turística Internacional - 2003. 2004c. Disponível em: <http://www.turismo.gov.br/site/arquivos/dados_fatos/demanda\%20turistica /Estudo\%20da\%20Demanda\%20Turistica\%20Internacional\%202003.pdf>. Acesso em: 13 Fev. 2006

EMBRATUR - Instituto Brasileiro do Turismo. 1999a. Estudos do Turismo Brasileiro, EMBRATUR, Ministério do Esporte e Turismo, Brasil

EMBRATUR - Instituto Brasileiro do Turismo. 1999b. Estudo da Demanda Turística Internacional, EMBRATUR, Ministério do Esporte e Turismo, Brasil

FAULKNER, B. 2003. A Model for the Evaluation of National Tourism Destination Marketing Programs, in FAULKNER, B. Aspects of Tourism - Progressing Tourism Research, Clevedon, Channel View Publications

GOSS, J. 1993. Placing the Market and Marketing Place: Tourist Advertisements of the Hawaiian Islands, Environment and Planning, Society and Space, V. 11, p. 663 - 688

GUNN, C. 1989. Vacationscape: Designing Tourist Regions, 2nd Edition, New York, Van Nostrand Reinhold

HAIR, Jr., J; BUSH, R. P.; ORTINAU, D. J. 2000. Marketing Research: A Practical Approach for the New Millennium, Boston: Irwin/McGraw-Hill

HAIR, Jr., J.; ANDERSON, R.; TATHAM, R. 1987. Multivariate Data Analysis - With Readings, Second Edition, New York, Macmillan Publishing Company

HUNT, J. 1991. The Impact of National Tourism Organisation Advertising Expenditures on the United States Traveller Market. Appendix G. in Evaluation of the Australian Tourism Commission's Marketing Impact. Sydney, Australian Tourism Commission 
HUYBERS, T. 2003. Domestic Tourism Destination Choices: A Choice Modelling Analysis, International Journal of Tourism Research, V. 5, p. 445 - 459

JOHNSON, R. A.; WICHERN, D. W. 1992. Applied Multivariate Statistical Analysis, Third Edition (international Edition), New York, Prentice Hall

KIM, S.; FESENMAIER, D. 1990. Evaluating Spatial Effects in Recreation Travel, Leisure Sciences, V. 12, p. $367-381$

KOTLER, P. 1990. Marketing: Edição Compacta, São Paulo, Editora Atlas

MALHOTRA, N. K. 1996. Marketing Research: An Applied Orientation, Second Edition, New York: Prentice Hall

MANSFELD, Y. 1990. Spatial Patterns of International Tourist Flows: Towards a Theoretical Framework, Progress in Human Geography, V. 14, p. 373 - 390

MOK, H. 1990. A Quasi-Experimental Measure of the Effectiveness of Destination Advertising: Some Evidence from Hawaii, Journal of Travel Research, V. 28, pp. 51 - 55

MOUTINHO, L. 1987. Consumer Behaviour in Tourism, European Journal of Marketing, V. 21 (10), p. $1-44$

MURPHY, P. 1985. Tourism - A Commodity Approach, New York, Methuen

NESLIN, S.; HENDERSON, C.; QUELCH, J. 1985. Consumer Promotions and the Acceleration of Product Purchases, Marketing Science, V. 4, p. 147 - 165

NUNALLY, J. C. 1978. Psychometric Theory, New York, McGraw-Hill

O'HAGAN, J.; HARRISON, M. 1984. Market Shares of U.S. Tourism Expenditure in Europe: An Economic Analysis, Applied Economics, V. 16, p. 919 - 931

PAPATHEODOROU, A. 2001. Why People Travel to Different Places, Annals of Tourism Research, 28 (1), p. $164-179$

PARASKEVOPOULOS, G. 1977. An Economic Analysis of International Tourism, Lecture Series 31, Athens, Centre for Planning and Economic Research

PARK, C.; ROUTH, M.; JACQUES, E. 1988. Evaluating the Effects of Advertising and Sales Promotion Campaigns, Industrial Marketing Management. V. 17, p. 129 - 140

PEARCE, D. 1987. Tourism Today - A Geographical Analysis, Burnt Mill, Longman

PEATTIE, K.; PEATTIE, S. 1996. Promotional Competitions: A Winning Tool for Tourism Marketing, Tourism Management, V. 17, p. 433 - 442

PIRES, J. 2004. Turismo no Brasil. Disponível em: <http://www.embratur.gov.br>. Acesso em 15 Set 2006.

RICHARDSON, J.; FLUKER, M. 2004. Understanding and Managing Tourism, Australia, Pearson Hospitality Press

SANTANA, G. 2001. Tourism in South America, New York, The Haworth Press 
SANTANA, G. 2000. A Contemporary Overview of Tourism Development in Brazil, International Journal of Contemporary Hospitality Management, V. 12 (7), p. 424 - 430

SCHNEIDER, S. 1999. EMBRATUR Calcula mais de 5 milhões de Empregos. (Pesquisa). Diário Catarinense, Caderno de Economia, 6 de Julho: 13

SMITH, V. 1989. Hosts and Guests: The Anthropology of Tourism, 2nd Edition, Philadelphia, University of Philadelphia Press

SYRAKAYA, E.; UYSAL, E.; TOEPPER, L. 1995. Measuring Tourism Performance Using a ShiftShare Analysis: The Case of South Carolina, Journal of Travel Research, 34 (Fall), p. 55 - 61

TELlIS, G., GAETH, G. 1990. Best Value, Price-seeking and Price Aversion: The Impact of Information and Learning on Consumer Choices, Journal of Marketing, V. 54, p. 34 - 45

WOODSIDE, A. 1990. Measuring the Advertising Effectiveness in Destination Marketing Strategies. Journal of Travel Research, V. 29 (Fall), p. $3-8$.

Recebido em: 18/10/2006 (1 ${ }^{\mathrm{a}}$ versão) 08/01/2007 ( $2^{\mathrm{a}}$ versão)

Aprovado em: 08/08/2007 